\title{
O ESTOICISMO COMO MODO DE VIDA NA ATUALIDADE: DESINSTITUCIONALIZAR PARA UNIVERSALIZAR
}

\section{Vilmar Prata ${ }^{1}$}

\begin{abstract}
RESUMO
Religião e ciência representam na história do pensamento e das práticas humanas dois polos de saberes marcados por inúmeros e grandes conflitos em cada um dos polos e entre eles. Esses conflitos foram deixando marcas e delineando os rumos da humanidade no decorrer dos séculos. Para além desses dois lugares de saberes, a filosofia, no seu papel de questionadora, ocupou e ocupa uma posição extremamente importante para que se pudesse evitar ou tentar evitar radicalismos de ambas as partes. Este texto traz uma breve crítica ao papel desempenhado pela religião e pela ciência enquanto instituições supostamente detentoras de seus respectivos saberes, apontando as falências e contradições teóricas e práticas de ambas. Tomo como ponto de partida o filósofo cristão Plantinga, em sua reflexão sobre o ajuste fino, fazendo um breve retorno ao filósofo estoico e imperador Marco Aurélio, através do pensador francês Michelet, tendo como pano de fundo a temática do processo de universalização e desinstitucionazação dos saberes, propondo o estoicismo como modo de vida para a atualidade.
\end{abstract}

Palavras-chave: Religião. Ciência. Desconstitucionalização. Estoicismo.

\begin{abstract}
Religion and science represent in the history of human thought and practices two poles of knowledge marked by numbers and great conflicts in each of the poles and between them. These conflicts have left their mark and delineated the direction of humanity over the centuries. In addition to these two places of knowledge, philosophy, in its role as a questioner, has occupied and occupies an extremely important position in order to avoid or try to avoid radicalism on both sides. This text briefly criticizes the role played by religion and science as institutions supposedly holding their respective knowledge, pointing out the theoretical and practical failures and contradictions of both. I take as a starting point the Christian philosopher Plantinga, in his reflection on fine tuning, making a brief return to the stoic philosopher and emperor Marco Aurélio, through the French thinker Michelet, having as a background the theme of the process of universalization and deinstitutionalization of knowledge, proposing stoicism as a way of life for today.
\end{abstract}

Keywords: Religion. Science. Deinstitutionalization. Stoicism.

\footnotetext{
${ }^{1}$ Doutorando em Filosofia pela Universidade Federal de Sergipe - UFS.

E-mail: vilmarlabedisco@gmail.com. ORCID: 0000-0001-9629-5461.
} 


\section{Crítica à religião e à ciência enquanto instituições}

Ao longo da história da humanidade, religião e ciência sempre ocuparam um lugar relevante nos embates filosóficos e teológicos, mas, ao afunilar mais o assunto, tomando como polos a contraditória fé cristã e as teorias que de fato são científicas e as que se dizem científicas, iremos entrar num outro campo de discussão que, por mais semelhante que seja em relação às teorias em torno da fé e da razão, encontraremos pontos específicos que dizem respeito à crença cristã e às suas variadas nuances sobre as ditas teorias científicas, ambas enquanto instituições políticas de poder.

É importante ressaltar antes de prosseguirmos que quando usamos o termo "contraditória" nos referindo à fé cristã, utilizamos porque, sem muito esmero, ao observar a história do cristianismo, notamos um discurso muito suntuoso referente ao amor e à caridade, porém, na prática, esse discurso é vazio e sem correspondência com a atuação da igreja, que se intitula a administradora dessa fé cristã, e, ressalto, que essa crítica não traz nada de novo, porém, fiz questão de me referir à fé cristã como contraditória, pois a considero muito mal representada pelos que dizem professá-la e muito alegórica em seu conteúdo.

E se tomarmos a mitologia grega para fazer um paralelo, me arrisco a dizer que, existe quase um plágio da história de Jesus Cristo em relação à história de Sócrates, se pensarmos ambos como portadores de um discursoverdade que podemos chamar de 'boa-nova' (conforme um termo utilizado pela própria igreja) para a humanidade e que morrem no final em nome do mesmo. A diferença é que Sócrates não foi transformado em deus e Jesus Cristo foi, e aí me pergunto: será que, com quais interesses?

A normatização institucionalizada do discurso-verdade, por meio do cristianismo enquanto instituição estruturada no modelo igreja católica, apostólica, romana e, posteriormente, em outras ramificações, foi, uma grande contribuição para que a filosofia perdesse seu lugar entre homens e mulheres como principal caminho de busca da verdade, questionando não só o modo como o homem tenta acessar o sobrenatural, mas, também, questionando a ciência, contribuindo de maneira inestimável ao desenvolvimento 
intelectual de toda humanidade, e, nos tempos atuais, ser tão pouco valorizada no cotidiano, seja da academia, seja, na sociedade como um todo.

No ocidente podemos testemunhar o despontar avassalador da religião e da ciência enquanto instituições políticas detentoras do poder, deixando a fé e a razão, enquanto foco principal, de lado, e, dando lugar à vaidade e ambição humana. A essência do discurso-verdade enquanto modo de vida, de sua prática autêntica no cotidiano de quem se propõe viver coerentemente em relação à verdade contida no discurso, que, por sinal, já era conteúdo de ensino e orientação na filosofia grega e que se estendeu ao estoicismo, dá lugar aos novos hábitos institucionais, e Foucault vai constatar que

Se a prática científica, a instituição científica, a integração ao consenso científico bastam, por si só, para garantir o acesso à verdade, é evidente que o problema da verdadeira vida como base necessária da prática de dizer-a-verdade desaparece. Confisco do problema da verdadeira vida, na instituição religiosa. Anulação do problema da verdadeira vida na instituição científica. Vocês compreendem porque a questão da verdadeira vida não parou de se extenuar, de se atenuar, de se eliminar, de se puir no pensamento ocidental. (FOUCAULT, 2011, p. 207)

Para ilustrar um pouco essa situação, tomarei um livro de filosofia da religião, ou talvez poderíamos chamar também livro de filosofia cristã, intitulado Ciência, Religião e Naturalismo, de um relevante autor americano chamado Plantinga ${ }^{2}$, que, no capítulo sete, vai tratar do Ajuste fino ${ }^{3}$, falando da convergência em relação à crença teísta e a ciência e levanta a questão:

um dos pontos de convergência seria a corroboração pela ciência da crença teísta. Já defendi a tese que a ciência não é conciliável com a crença cristã. Poderemos ir mais longe e afirmar que ela corrobora a crença teísta? (...) De que modo a ciência poderia fazer isso? (PLANTINGA, 2018, p. 177).

Porém, gostaria de propor aqui, inverter a questão e perguntar: a fé teísta corrobora com a ciência? De que modo a crença teísta poderia fazer

\footnotetext{
2 Alvin Plantinga é um filósofo analítico, conhecido por seu trabalho na filosofia da religião, epistemologia, metafísica e apologética. Alguns de seus argumentos incluem o argumento ontológico modal, o argumento evolutivo contra o naturalismo, a melhor teodiceia possível do mundo e a epistemologia reformada. Seus críticos afirmaram que ele é um defensor do design inteligente, embora ele negue isso dizendo que ele é um cristão criacionista. Ele é autor de vários livros, incluindo Deus e outras mentes, A natureza da necessidade, Crença cristã garantida e Onde o conflito realmente se encontra.

${ }^{3} \mathrm{O}$ ajuste fino é um argumento da física e cosmologia para a criação divina do universo. Será mostrado que descobertas da física e cosmologia nos últimos cinquenta anos dão grande apoio à existência de Deus e à criação divina do universo.
} 
isso? Existe de fato algum ou alguns pontos de convergência entre as duas, e se existe, quais seriam esses pontos de convergência?

Parece que existe uma preocupação exacerbada por parte do teísmo em querer provar a veracidade e a necessidade de se professar uma fé em relação a um determinado deus, e mais ainda, que essa fé, e podemos indicá-la especificamente como a crença cristã, esteja de acordo com os parâmetros institucionais que a representa e a organiza conforme uma suposta inspiração divina. Mas então quem determina essa tal inspiração divina? Quem a distingue de uma mera intuição humana, baseada em interesses pessoais de grupos minoritários que detêm o poder e de uma inspiração divina de fato?

Uma vez que, sem muito esforço, percebe-se ao longo da história uma disputa imatura, senão realmente infantil, entre os próprios membros de tais instituições disputando o poder, e, para além de seus embates internos, querendo provar e impor aos que não professam e comungam da mesma fé uma necessidade existencial que se alastra por todos os lados, seja econômico, político e jurídico, um discurso de que é extremamente necessário e urgente confiar no deus que eles propõem, e mais ainda, submeter ao aval institucional que estabelece o que é certo e/ou errado no caminho para se aproximar desse deus, visando previsivelmente a tal suposta e desejada salvação.

Mas salvação de que mesmo? Do inferno? Do castigo eterno? Ora, na atualidade, tais argumentos não convencem, mesmo se olharmos pela posição dos próprios teístas cristãos, uma vez que, se esse deus é amor e é amor incondicional, o argumento do livre arbítrio, de que o homem escolhe seu próprio caminho, e é livre para aceitar ou não esse amor divino não convence, pois se de fato esse tal deus é amor, e é um amor incondicional e criador, como pregam contraditoriamente, a conduta do homem, supostamente não deveria influenciar o sentimento desse deus tão amoroso e poderoso. $\mathrm{Ou}$ seja, a deus não se atribui sentimentos tipicamente humanos e, para ele, independente da postura do homem em relação ao seu amor, não o afetaria, e ao homem, enquanto criatura, por mais que se considere livre para fazer escolhas, seria impossível se desvencilhar do próprio criador, pois o homem em si é parte desse criador, assim como todas as criaturas criadas por ele, que, a priori, não são portadores do que denominamos de livre arbítrio. 
Então, qual é a necessidade dessa criação feita pelos próprios homens de impor uma fé, uma determinada fé e organizarem grupos que se intitulam administradores da crença alheia e, arrogantemente, posicionam-se como representantes desse deus, desse poder divino?

Seria pura vaidade intelectual? Ou mesmo, vaidade espiritual? Plantinga apresenta em seu trabalho alguns argumentos que defendem a existência de um deus que se ligam à teoria intitulada como design inteligente. Segundo o texto, esse design inteligente seria deus, e estaria respaldado pelo argumento do ajuste fino e por argumentos embasados na biologia.

Plantinga (2018, p. 178) afirma que "descobertas científicas acerca da estrutura do Universo, na Física e na Astronomia, fornecem as premissas de um argumento teísta" e que a biologia seria em si a prova cabal de um suposto organizador, design, como preferirem denominar, de que o que está aí, vivo, não poderia simplesmente viver e existir por simples espontaneidade ou causalidade.

Essa necessidade quase doentia de querer disputar lugar com a ciência, de querer tomar para si todos os conhecimentos a favor de um sustentáculo que viabilize a teoria religiosa, não é característica apenas de Plantinga, mas se observa em muitos teólogos, filósofos cristãos e demais teóricos que professam algum tipo de fé. Muitos vão justificar essa inquietude defensiva como meio de proteção aos supostos ataques dos cientistas e filósofos ateus ou não, que apontam quase que naturalmente em seu conteúdo as lacunas e as contradições do teísmo, e mais especificamente do cristianismo.

Ora, se tomarmos especificamente a relação entre ciência e religião, constataremos que, quando um cientista apresenta uma teoria a respeito de qualquer fenômeno, não se vê, de modo geral, como objetivo último a simples intensão de criticar ou derrubar o teísmo, nem a crença cristã. Percebese que existe, sim, uma vontade de conhecer, de aprender, de explorar o mundo a sua volta, para tentar, talvez, melhorar um pouco o modo de vida da humanidade na terra e das demais criaturas. Claro que, nesse movimento científico, muitos erros são cometidos contra a própria natureza e contra a própria espécie humana, mas dizer que a ciência movimenta-se com o único objetivo de disputar lugar com a fé, seria, a meu ver, equivocado. 
Tão equivocado que o próprio Isaac Newton, citado por Plantinga, vai afirmar que "este sistema belíssimo, formado pelo sol, os planetas e os cometas, só pode proceder da prudência e do domínio de um ser inteligente e poderoso". Reforçando que, sua intensão ao pesquisar, ao buscar conhecer e decifrar os mistérios do planeta, não era única e exclusivamente derrubar a teoria da crença cristã, não era ridicularizar a fé teísta, não era, por mais que fosse divergente das propostas dos 'escolhidos de deus', dos representantesadministradores da fé, dizer que a existência de um deus para se adorar estivesse errado. Nesse contexto, o próprio Newton, como cientista, mostra-se aberto à possibilidade da existência de um ser inteligente que organiza e cria todo universo.

Nesta perspectiva, justificar muitas vezes de maneira insistente, fazendo interpretações tendenciosas e irônicas de grandes filósofos da história, esta ânsia de querer provar que o teísmo, tem respaldos aceitáveis e coerentes parece uma paranoia que consome os intitulados filósofos cristãos e os demais teístas que se debruçam e se esforçam em tomar convenientemente a ciência, ora como parceira, ora como uma ameaça ao império teístacristão que vigora ao longo dos séculos. Essa relação com a ciência, por fim, acaba por se tornar, por parte da religião, uma relação exageradamente defensiva, arredia e sempre alerta aos ataques teóricos.

Talvez seria mais coerente que se os cristãos teístas, com o tempo dedicado a provar a validade de sua fé, direcionasse a imitar, na prática, Jesus Cristo, tomando como um dos exemplos de representatividade divina, amando o próximo como a si mesmo, mas não teoricamente, não repetindo como papagaios dentro de suas igrejas ou nos grupinhos que comungam da mesma ideia. Mas, assim como Cristo, amar de fato o outro em suas diferenças, demonstrar com práticas, sem esperar salvação ou nada em troca, sem esperar reconhecimentos sociais ou divinos, assim como buscavam fazer os estoicos em relação ao conteúdo filosófico que ensinavam e aprendiam.

Simplesmente amar, se colocar no lugar do outro. Penso que, se de fato esses teóricos cristãos que tentam a todo custo dizer que a fé faz tanto sentido quanto a razão, que a crença teísta é tão confiável quanto a ciência, começassem a ser coerentes com o discurso objetivo e simples sobre o tal deus que pregam, não tenho dúvidas, o mundo estaria muito melhor, e tal- 
vez, todos iriam querer comungar e professar da mesma fé. Mas, tomando as próprias palavras de Cristo, não passam de "sepulcros caiados", lindos por fora, podres e vazios por dentro, cheio apenas do mal cheiro e da incoerência que compõem suas posições sociais.

\section{O estoicismo como modo de vida na atualidade}

Questionar a crença cristã no que tange a sua real necessidade de existir nas sociedades humanas faz tanto sentido, quando se questionou o poder de alguns imperadores romanos e, assim, foram consumidos pela própria ganância e exageros de poder. Tomo esse exemplo porque é semelhante ao império cristão enquanto instituição política de poder e o que já foi um dia o império romano, se fragmentando pelos disparates gananciosos de sua própria cúpula eclesiástica, desmoronando por não conseguir mais sustentar o peso de tantos dogmas incoerentes com a prática, que nem eles conseguem dá conta.

Para além da crença teísta, mais especificamente a cristã, que ainda vigora no ocidente, o homem da atualidade tem notado, ou precisa notar, que já passou da hora de começar uma relação menos antropocêntrica consigo mesmo, com o outro, com o mundo em que vive e com o universo no qual este mundo está inserido, porque simplesmente o homem não é o centro do universo, como já ficou claro em teorias pós-moderna, pós-estruturalista, teorias sobre a subjetividade do sujeito e da nova história. O homem precisa se desvincular dos preconceitos, da arrogância e das paixões, aprendidos socialmente e estabelecidos como padrão de comportamento. Hadot nos mostra que pelo estoicismo se é possível

libertar a imaginação das representações passionais do arrependimento e da esperança, libertar-se assim de inquietações ou de preocupações inúteis, mas sobretudo praticar um verdadeiro exercício da presença da natureza, renovando a cada instante o consentimento da nossa vontade, a vontade da natureza universal. (HADOT, 2014, p.86)

Talvez poderíamos pensar hoje, numa urgente necessidade de retorno às raízes estoicas como modo de vida, dos ensinamentos e orientações de como se relacionar consigo, com o outro e com o universo, dando atenção 
ao que realmente importa. Chegou ou está chegando o tempo em que será exigido do homem estabelecer uma relação mais voltada para perspectiva geral da natureza como propõe o estoicismo, da sua própria natureza, e não de teorias vazias e sustentadas por instituições falidas como o próprio cristianismo e até mesmo como a própria ciência, que por mais empírica que seja, muitas vezes não consegue ir além da ganancia financeira, do egoísmo humano, usando o planeta sem o mínimo de responsabilidade ecológica.

Antes mesmo do cristianismo surgir entre os homens, a ideia de uma razão universal, que organiza e ordena o mundo, o universo e todas as criaturas que neles vivem, já era apresentada e debatida. Nesse movimento a razão humana se consolidou como o alicerce da comunidade e da complexa organização social em suas diversas etapas, estabelecendo aparentemente um organismo socialmente humano dentro do organismo universal, que, fora dele, simplesmente não existe comunidade humana, nem sequer, o próprio homem.

Se, portanto, a razão humana produziu, organizou e estabeleceu as regras do convívio social interno e com o mundo à sua volta, ela acabou por ousar querer não só conhecer o mundo, o universo, o cosmo, mas como criar um universo para si, com sua cara, com seu jeito, daí surge a ideia dos deuses, ou de um único deus, com características humanas e até mesmo com sexualidade definida. Afinal, pensar um deus feminino é simplesmente inconcebível para a crença cristã, ou estaria eu equivocado?

Para pensarmos essa volta ao estoicismo como modo de vida, gostaria de lembrar aqui o filósofo francês do século XIX, Michelet, que, tomando a partir de 1820 como uma de suas principais leituras, As Meditações de Marco Aurélio, vai estabelecer para si um paralelo entre o que ele chama de pátria humana e pátria cósmica. Para ele, essas duas realidades, social e universalmente natural, são simplesmente a base de toda forma de vida, que encontra seu ponto de convergência mediante a dedicação humana para a própria preservação, conforme a preservação do planeta.

Em certa ocasião, em um de seus diários, datado do dia 7 de agosto de 1831, já escrito sob influência de Marco Aurélio, ele vai expressar 
O geral, o universal, o eterno, eis a pátria do homem. É a ti que pedirei socorro, meu nobre país: é preciso que tu ocupes para nós o lugar do Deus que nos escapa, que tu preenchas em nós o incomensurável abismo que o cristianismo extinto deixou. Deve-nos o equivalente do infinito. Todos sentimentos a individualidade morrer em nós. Que possa recomeçar o sentimento da generalidade social, da universalidade humana, daquela do mundo! Então talvez nos elevemos para Deus. (Journal, t. I, p. 83)

Assim como para os estoicos, essa concepção universal da vida tornou-se para Michelet de suma importância, é um princípio de existência, um modo de aprendizagem e de se ligar ao cosmos por meio da própria história, de suas escolhas individuais e das escolhas tomadas pela sociedade em que se está inserido.

Ele ainda pontua o desfavor que o cristianismo prestou em sua época afastando o homem do verdadeiro sentido da vida. Este mesmo homem que se constitui, desta maneira, pela história que desenvolve junto aos seus e junto ao mundo, mantendo uma linha tênue entre o passado, presente e futuro. Se esse vínculo, porventura é quebrado, é desrespeitado, mergulha-se num caos pessoal, social e universal, exatamente o que vivemos nos tempos de hoje. Afinal, não há como entender e manter relação com seja lá o que for, sem antes, entender o meio e o modo como se organiza dentro da conjuntura universal. Em uma de suas orientações, Marco Aurélio afirma que

todas as coisas estão entrelaçadas umas nas outras e essas conexões são sagradas: de algum modo, nenhuma é estranha a outra, pois cada uma está coordenada às outras e ela contribui para ordenar a ordem do mundo, pois uma só ordem do mundo resulta de todas as coisas e um só deus percorre todas as coisas e uma só substância e uma só lei: a Razão que é comum a todos os viventes dotados de pensamento. (MARCO AURELIO, VII, 9)

Nota-se que o conceito de deus e razão são muito similares e que o que prevalece é a ordem, o planejamento, a vontade de uma força maior, em querer formar e ver o universo e tudo que lhe diz respeito em movimento harmonioso e coerente e não ficar debatendo se um deus personalizado existe ou não, disputando lugar com áreas específicas do saber. Nota-se que a crença cristã não traz novidade alguma, Marco Aurélio, e tantos outros, bem antes já pensara, já refletia sobre tal possibilidade, porém, ainda, sem a arrogância institucional do cristianismo, representada pela igreja católica e de- 
pois, insustentavelmente e previsivelmente foi se fragmentando em outras ramificações institucionais, a saber, protestantes, ortodoxos, pentecostais e tantos outros, que comungam da mesma postura: arrogância religiosa, mas que não se sustentam quando o assunto é amor ao próximo.

Marco Aurélio inspirou muito Michelet em seus escritos a formar sua concepção de mundo e de homem, e mais ainda, de compreender a relação do homem consigo mesmo e com o mundo. De analisar em seu tempo, de modo cauteloso, as posições da religião e da ciência enquanto instituições de saber. Ainda em sua obra Discurso sobre a unidade da Ciência, notamos tal influência ao tomar o próprio Marco Aurélio como assunto:

quer ele observe as leis invariáveis da física ou as leis não menos regulares às quais estão sujeitas as tarefas humanas em sua mutabilidade aparente, ele reconhece uma mesma concepção, uma mesma vontade. A ciência então aparece a ele como um sistema sagrado, do qual se deve temer separar as diversas partes. Ele só divide para recompor, só estuda os detalhes para elevar-se à inteligência do conjunto; ser fraco, é bem necessário que ele consagre mais especialmente seus trabalhos a um ramo dos conhecimentos; mas infeliz dele se tentasse se isolar de todo o resto! Ele poderia observar fatos, não poderia apreender o espírito que os vivifica. Ele se tornaria erudito talvez, jamais esclarecido; a dignidade, a moralidade da ciência, permaneceria estranhas a ele. Longe de vocês, jovens alunos, essa ciência morta e infecunda! Preparados pelos estudos clássicos para aqueles da vida, vocês carregarão o distanciamento que nós lhes inspiramos por esta parcialidade do espírito, por essa estrita preocupação, que favorece um exercício do espírito em detrimento de todos os outros; vocês não dirão as ciências, mas a Ciência; vocês não esquecerão que o conhecimento dos fatos isolados é estéril e frequentemente funesto; que o dos fatos ligados sob suas verdadeiras relações é todo luz, todo moral, todo religião. (MICHELET, 1867, p. 254)

O modo como Michelet toma a ciência, mediante inspiração do estoico imperador, permite vislumbrar uma outra forma de relação do homem com a ciência e até mesmo com a própria religião. Uma relação em que a unidade universal, que posso entender aqui como um agir conectado à natureza, ao respeito pelo planeta, não colocando o homem como o centro do universo, mas como parte desse universo, cuja responsabilidade em grau maior ou menor, resume-se em cumprir seu papel em toda sua potencialidade existencial.

A ciência ao ser colocada, assim como a religião, sob a coroa da instituição, corre o risco e se precipita numa série de equívocos que comprome- 
tem a vida entre os homens e suas vidas no planeta. Assim como a religião, a ciência acaba por transformar contraditoriamente os homens em semideuses e ao mesmo tempo em bestas que se agridem em disputas de poder, e, nesse mesmo movimento, elevar toda responsabilidade para o deus no qual deposita toda sua dissimulada devoção. Essa postura religiosa faz com que se atribua graça e desgraça a seres sobrenaturais, enquanto indivíduos se eximem da responsabilidade como seres humanos.

Essa preocupação, portanto, desvia o foco da humanidade. Seja o homem religioso seja o homem cientista, a preocupação em tentar provar quem está mais certo, quem precisa mais de quem, uma preocupação movida por vaidade institucional, que se desdobra em processos históricos, cujo resultado, ao analisarmos, não veremos nada mais, nada menos que um progresso vazio do próprio significado da palavra progresso.

Talvez o diferencial do homem, enquanto criatura, não seja simplesmente em ser um animal racional, mas para além disso, é ter consciência de sua universalidade e como pode contribuir para a plena harmonia do universo, do mundo em que vive. Talvez precisemos admitir que, é chegada a hora do homem atual se desinstitucionalizar, desinstitucionalizar deus no campo da crença e a natureza, no campo da ciência, e começar a assumir seu lugar no universo, redundantemente, como ser universal. É chegada a hora de pensarmos na pertinente possibilidade de adotarmos o estoicismo como um modo de vida, modo este que oferece ao homem a viabilização de se harmonizar consigo e com o universo.

\section{Referências}

FOUCAULT, Michel. A coragem da verdade: O governo de si e dos outros II. São Paulo: Martins Fontes, 2011.

HADOT, P. Exercícios espirituais e filosofia antiga. Tradução de F. Loque e L. Oliveira. São Paulo: É Realizações, 2014.

PlANTINGA, A. (2018). Ciência, Religião e Naturalismo: Onde está o conflito? Trad. Marcelo Cipolla, São Paulo. Ed. Vida Nova,

MARCO AURÉLIO. Meditações. Introdução, tradução e notas de Jaime Bruna. Editora Cultrix, São Paulo, 1989. 
Perspectiva Filosófica, vol. 47, n. 1, 2020

MICHELET, J. (2014). Discurso sobre a Unidade da Ciência. Trad. Flávio Fontenelle. São Paulo. Ed. É Realizações. 